\title{
A Review on the Design of Chimney for Air Cooled Condenser
}

\author{
Kuldeep Dehariya \\ M.Tech Scholar \\ Department of Mechanical Engineering \\ NRI Institute of Research \& Technology \\ Bhopal (M.P.), India \\ dehariya.karan73@gmail.com
}

\author{
Prof. Sunil Kumar Chatruvedi \\ Assistant Professor \\ Department of Mechanical Engineering \\ NRI Institute of Research \& Technology \\ Bhopal (M.P.), India
}

\begin{abstract}
Wind coils were used in the US electricity company in the early 1970s, however the amount of facilities has skyrocketed within last 10-15 years, due mainly to an increasing emphasis on green security. In addition, as the consumption of water grows in both household and commercial settings, more people are interested in using wind condensers. The Passively Cooled Compressor and its Contest is the topic of this article. This monthly bases the components of a wind capacitor.
\end{abstract}

Keywords: Heat exchanger, CFD, Condenser, Thermal power.

\section{INTRODUCTION}

A heat power station tree with a water drive shaft. Hot water, then converted to heat, which spins a turbine that drives an external power supply. The water is pared down in a compressor and reused to where it was roasted upon passing thru the propeller; this is recognised as the Carnot cycle. The heat from the burning fuel in the combustion chamber is used to produce steam in the heater of a thermal system. The steam passes thru a steam generator, which converts some of its heat mechanical work, which is then used to produce energyThe reheat from the heat pump condenses in the capacitor, which then feeds the droplets back into the stove via the feed tank, completing the loop. The Boiler's purpose is to produce steam. The condenser's job is to compress the steam that comes out of the reduced generator. The boiler turbine's job is to transform heat into electricity. The condenser's job is to raise the condensate's stress from the condensation temperature to the superheated steam.

Condenser: The purpose of a capacitor in a power station is to boost productivity by lowering the heat vent stress below air pressure. Some other benefit of the capacitor is that the compressed heat can be retrieved and used to continue providing good classic feed water to the heater, reducing the liquid softening ability significantly. One of these is a microphone. an electricity soil's critical ingredients A compressor is a heat exchange machine or unit that is used to compress a gases material into a liquid form by heating it. As a result, the material releases its heat capacity, which is transferred to the capacitor refrigerant. Air conditioners are heaters that come in a variety of shapes and styles, ranging from small palm components to big manufacturing components used in production systems. A fridge, for instance, uses a capacitor to transfer heat of the unit towards the outside sky. Air conditioners and factory biochemical mechanisms both use condensers. Evaporation, boiler power stations, and other heat-transfer structures are examples. In many capacitors, cold water or ambient air is used as the refrigerant. The primary function of a capacitor is to collect and consolidate heat from a steam power or generator. The advantage is that the electricity that would otherwise be wasted is put to good use. A heat capacitor reduces pressure of heat to a level below pressure and temperature. This enables the generator or engine to perform additional tasks. The release heat is also converted to nourish water, which is then brought back to the reboiler or boiler by the compressor. The dormant heat of vaporization is transferred to the coolant fluid water that flows thru the cooling channels in the capacitor.

\section{LiteratURE REVIEW}

Haiteng Ma et al. [1] The communication of heat transfer flow for air flow of a solitary heating chamber was probed first in this paper. Simulations using turbulence models were used, and data from the literature was used to verify them. The air temp of the heat dust cloud reduces as it evolves due to heat dispersion into the cooler ambience, but its speed increases, and the stream eventually transitions to wind gusts due to enlarged unrest, according to a thorough Flow field.

Zhu Xiaojing et al. [2] The achievement of a dehumidification capacitor with a lateral ellipsoidal tubing was investigated in this article. The impacts of essential factors on heat transport achievement, such as squirt intensity, anterior air speed, heat flux, and moisture, were discussed extensively. The dew point has a larger effect on thermal efficiency than the moisture content of all the studied traits.

Ankur Kumar et al. [3] The effectiveness of the blades is observed to reduce as the Rayleigh number, allows to quickly, and amount of pipe second row rise. The Taguchi was used to design, and mathematical results were obtained. For optimal capacitor achievement, the amount of pipe lines should be managed to keep anywhere from 2 and 4, fin padding 3-5 mm, pipe inning about $40 \mathrm{~mm}$, and tail altitude $5 \mathrm{~mm}$. 
Fei Duan et al. [4] that the temperature difference from an occasional wavy fin is considerably higher than a plain fin. The lateral load eddies can be produced by the corrugated channel of the occasional wavy furred flat tubing. Temperature distribution is improved by latitudinal eddies, but heat flux is reduced by evasive maneuvering vortices. Nusselt is not determined solely by the intensity of lateral load vortices in all setups. On the tail of an occasional wavy filleted flat tube, proposals for enhancing thermal performance are acquired. The ripple distance is $9.5 \mathrm{~mm}$, and the incident wave is 2.3 $\mathrm{mm}$, so the fin distance is $3.0 \mathrm{~mm}$, wave padding is $9.5 \mathrm{~mm}$, and incident wave is $2.3 \mathrm{~mm}$.

\section{Air CoOled Condenser}

A vacuum pump that chills a circulatory liquid within circular tube by trying to force airflow over the pipes' facade is known as a cooling system capacitor. A car heater is an instance of a wind capacitor. There are two main reasons why air heater coolants are used.

1. They are a great option to chillers and tubular heat regenerators since

2. they do not involve an ancillary groundwater

(water lost due to drift and evaporation, plus no water treatment chemicals are required).

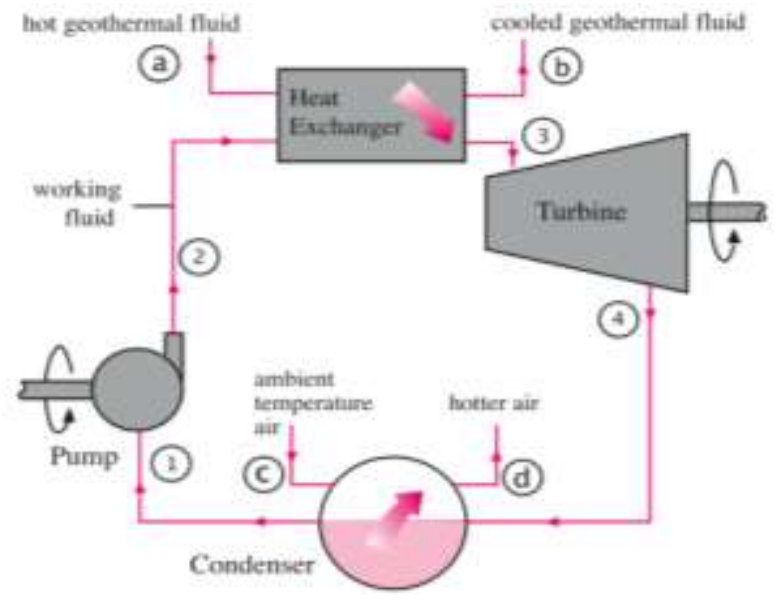

Fig. 1 Schematic for an air-cooled binary Rankine cycle

Wind heat exchangers can be as tiny as a cooling system or as big as so many hectares of land, as in the case of big electricity generation coolers. When the site location and environmental parameters prevent the simple and cost-effective use of other coolers, air-cooled heat exchangers are used. The following are the most obvious benefits of air-cooled condensers:

a) No issue with heat and chemical pollution of cooling fluids;

b) Versatility for any plant site and storyline strategy agreement because refrigerating hardware does not need to be near a stockpile of cooling water.

c) Lowering maintenance

d) Simple to set up e) Less of an ecological impact than a liquid capacitor due to the lack of an ancillary waterways, which saves water. f) Without need for coolants or a fire suppression system.

In cooling and plane application areas, wind furred condenser mics are commonly used. Wind coils are more cost-effective than liquid capacitors for the same level of heat handover. Most wind coils are from the round pipe and fin sort. Various method, such as improving the pipe wall exterior, shifting the tube geometrical by round to flat, and adding outer fins, can be used to boost the effectiveness of wind capacitors.

\section{Air Cool Condenser Challenges}

Since the heat conductivity of air is that much lesser than that of liquid, wind condenser mics tend to require much higher outlay than sweaty capacitors. As a result, the layout usually involves large heat impellers, vast fin regions, and structural components. For the reasons stated above, setup and operating costs for ACC processes are approximately 3.5 to 5 times higher than for wet chiller systems. Thermal efficiency must be enhanced in attempt to lessen setup and operating costs and to boost productivity.

As a result, the average temperature distinction ITD = (Tsteam,in - Tair,in) must be enhanced to improve thermal rate. However, increasing the steam inlet pressure causes a rise in condensed water generator back stress, which reduces the steam cycle energy yield by 5-6 percent when compared to a wet coolant. According to statistics, a $3 \mathrm{~K}$ increase in ITD results in a 1.1 percent reduced power creation.

Next great hurdle occurs during the season, whenever the electricity demand is high and the atmospheric temperature is raised, increasing heat condensed water stress and result in decreased energy output. Including in conditions where the wind direction is strong, the air intake warm air in the impeller of the fan rises due to backflow, lowering the thermal efficiency; similarly, pass fluid wind caused a spike in rightwards, resulting in high equine energy usage.

\section{Parts of Air Cooled Condenser.}

The exhaust rubber gasket is the starting point for a space heat capacitor system. It comes with everything you'll need to compress vapour and come back the droplets to the boiler's feed water pipework. These are the objects:

1. A steam capacitor tower that is kept cool by air.

2. Flight control hardware is number two.

3. Cell separation barricades and/or air.

4. Baseboard heater with steam underpass.

5. Hardware for removing air.

6. A holding tank for water vapour.

Flushes for water vapour.

8. Growth openings and vapour ducts

9. Plane pipework and ethane drain. 


\section{Limits and alert for percussion.}

11. Vapour vent cylinder safety with a stress gadget.

12. Vapour condenser water scheme.

Packs, steam flowline, enthusiasts, engines, planetary gears, and sponsoring metal are all included in the fundamental wind boiler capacitor. The price of the tower structure that supports the capacitor multipacks can make up a significant portion of the overall cost in larger buildings. Loading, storey drift, load, and seismographic necessities should all be cautiously considered when designing the framework. In overall, turrets that are assembled on the ground are less expensive than those that are assembled on the roof. The investigation description must specify any restrictions on show a typical. Heat supplies that discharge into the ambience and are near to the suggested mast must be recognised. The appropriate position and alignment of the mast in relation to other big constructions and heat references is determined by the wind patterns ways. Season winds play a role in determining thermal efficiency, and cold winds play a role in determining cryo metrics. Lesser fan noise usually necessitates a lesser tip pace, the most exhaust systems, and potentially broad razors, so noise constraints should be noted. The thermal efficiency assurances should be based on steam pressure is determined at the compressor flange or at the vapour myriad cove at the condenser, as specified by the buyer. Some all scheme, which reduces the risk of air leakage into the capacitor, and the use of extrusion aluminium fins are two other choices. which last longer than engrained or tie fins and are less likely to fail (these are prone to galvanic corrosion because of their bimetallic tube-to-fin interface). Despite being an integrated component of the product's designed bundle, air circulation control box for cold safeguard reflects the buyer's needs and demands. Varying fans, flight control louvres, thermal alienating vents, and 2 different engines should all be considered. Battery powered starters, which are required for two-speed motors, should be factored in. Air walls are often required to protect the packages from gusty winds that can disrupt the balance of the building's operational conditions and even cause ice formation in some remote areas. Operating cells are separated from quasi cells by partitions among fan molecules. Without partitions, a non-functioning supporter would cause air destined for the bundles to circumvent. It may be cost-effective provide a vapour gas boiler for chilly setup, guess it depends on the minimum design environmental noise air temp, the sort of generator, and the category of production line. It would run directly from the heater, needing both a vapour pneumatically depot and a tres depot, with vapour expending into the main steam tubing. All through setup, part of the capacitor heaters water would come from the generator engine, and the rest from this circumvent scheme. Put another way, Large water vents can be managed to install to successively to provide capacitor segments with vapour derived solely from the generator engine.

\section{CONCLUSION}

The primary goal of this research is to judge the effectiveness of wind capacitors in a variety of situations. Increased acoustic sun 's heat wind patterns degrade the efficiency of air-cooled capacitors. Wind-blocking walls are used to mitigate the effects of the wind. The speed of the fan can also be enhanced. Changing the ACC of the air-conditioning unit's shading reduces the high temp caused by solar radioactivity.

\section{REFERENCES}

[1] Haiteng Ma, Sham Rane "Heat Transfer-Fluid Flow Interaction in Natural Convection around Heated Cylinder and Its Thermal Chimney Effect", Conference: International Conference on Innovative Applied Energy - 2019

[2] Zhu Xiaojing, Chen Shi, Shen Shengqiang, Ni Shuangquan, Shi Xu, Qiu Qinggang (2020), "Experimental study on the heat and mass transfer characteristics of air-water two-phase flow in an evaporative condenser with a horizontal elliptical tube bundle", Applied Thermal Engineering Volume 168, 5 March 2020, 114825.

[3] Ankur Kumar, Jyeshtharaj B. Joshi, Arun K. Nayak, Pallippattu K. Vijayan, "3D CFD simulations of air cooled condenser-III: Thermalhydraulic characteristics and design optimization under forced convection conditions", International Journal of Heat and Mass Transfer 93 (2016) 1227-1247.

[4] Fei Duan, KeWei Song, HouRan Li, LiMin Chang, YongHeng Zhang, LiangBi Wang, "Numerical study of laminar flow and heat transfer characteristics in the fin side of the intermittent wavy finned flat tube heat exchanger", Applied Thermal Engineering 103 (2016) 112-127.

[5] A.Rupeshkumar V. Ramani, B. Amitesh Paul, D. Anjana D. Saparia Nirma University Ahmadabad (December 2011) Performance Characteristics of an Air-Cooled Condenser under Ambient Conditions. NUiCONE 2011

[6] Johan Adam Heynes and D.G Kroger University of stellenbosh (December 2008) enhancement in cooling performance using a Dry/Wet Dephlegmator when ambient temperatures are high.

[7] EA.I.ElSherbini and G. P. Maheshwari Building and Energy Technologies Department Kuwait Institute for Scientific Research (October-2010). ESL-IC-10-10-52 Effectiveness of Shading Air-Cooled Condensers of Air-Conditioning Systems. 